\title{
perifèria
}

Número 16, junio 2012

revistes.uab.cat/periferia - www.periferia.name

\section{"La cuestión no es si sabemos bastante: la cuestión es si tenemos el valor de saber lo que sabemos, decirlo y usarlo"}

\author{
Juanjo Conesa - Escola d"Adults de Berga
}

En primer lugar, debo agradecer a la familia de Ramón, especialmente a su hija María y a Cristina, su esposa, que me hayan invitado al homenaje a mi maestro. Para mí es un honor y una enorme satisfacción poder acompañarles hoy. Dicho esto, les hablaré del hombre que yo conocí. Intentaré ser breve, no se preocupen: no vengo a contar su vida, sino a celebrarla.

La verdad es que la primera vez que Ramón me dijo, mucho antes de que se manifestara su enfermedad, "Yo no sé quién soy" me quedé estupefacto. Lo afirmaba con rotundidad y sin la menor sombra de pesadumbre -y eso era, seguramente, lo que más me sorprendía, porque a mi sí que me preocupaba e interesaba saber quién era yo. En cambio, Ramón manifestaba su ignorancia sin ninguna inquietud. No lo decía tampoco con vanidad: naturalmente, no era su aserto un trasunto del manifiesto socrático de ignorancia. No, la afirmación de Ramón me parecía mucho más desesperanzada y desolada. Sin embargo, no lo era: Ramón lo decía simplemente como una advertencia. Era una forma de decir "En ese asunto no puedo ayudarte; si sigues por ahí, lo harás solo".

Conocí a Ramón hace aproximadamente quince años; fui su alumno siempre que pude y, como otros muchos alumnos, durante ese periodo de mi vida y después de terminar la carrera, compartí con él conversaciones académicas y extraacadémicas y se lo oí decir más de una vez: "yo no sé quién soy".

La primera vez hablábamos de moral. Quisiera estar seguro de lo que acabo de decirles, pero no lo estoy. De lo que sí estoy seguro es de que, en aquellos momentos, yo pasaba por una situación muy difícil, me encontraba en una encrucijada personal y eso se notaba también en mis trabajos. Fue mientras

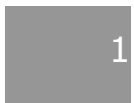




\section{perifèria \\ Número 16, junio 2012 \\ revistes.uab.cat/periferia - www.periferia.name}

comentábamos uno de ellos cuando lo dijo. Su afirmación me inquietó entonces y me sigue inquietando ahora. Quiero decir que me turbaba, y me asombra, la serenidad con que lo manifestaba.

Tengo la impresión de que Ramón no siempre asumió esa ignorancia con la misma tranquilidad. Cuando yo le conocí se aproximaba a los setenta y, posiblemente, había abandonado ya el combate. Me refiero a ese combate que cada uno libra contra sí mismo, por el que cada uno descubre y comprende quién es sólo para volver a enfrentarse a sí mismo y ser descabalgado, comprender su error - y con su error, otra vez a sí mismo, quizá ya otro. El combate en el que, por su propia naturaleza, siempre vencemos y siempre somos derrotados por no sabemos quien.

Ramón me decía, a finales de los noventa, antes de despedirse de la Autónoma, que se había ido jubilando poco a poco -y no se refería únicamente a su trabajo. La lucha, la agonía se desarrollaba en la trastienda de su espíritu o quizá había ya cesado. Sin embargo, hay jirones de su memoria en mi memoria y le recuerdo hablándonos de tecnología e instrumentos en clase de una asignatura que se llamaba "Cambio económico y social", durante una de aquellas brillantes e improvisadas digresiones tan suyas, celebrando, en este caso, la riqueza de la lengua castellana: de pronto da con una expresión... le viene a las mientes "recado de escribir" -"iqué hermosa expresión!", dice y se emociona evocando, de forma escueta, una historia vivida hace mucho tiempo: un periodo tormentoso de su vida, una pensión en un lugar remoto de la geografía española donde se ha encerrado por unos días, prácticamente sin equipaje. Necesita anotar todo lo que se le ocurre y siente y no tiene con qué. Se lo dice a la posadera. "¿Quiere usted recado de escribir?" -le pregunta ella- y le trae unas cuartillas y un lápiz pequeñito, muy gastado, con el que intenta poner negro sobre blanco la verdad del trance inhóspito en el que se encuentra.

Así eran sus clases. Llegaba por la mañana, muy temprano, para las lecciones de primera hora, puntualmente, pero ya con el paso cansado y lento, su cartera de piel marrón colgada a un hombro y la sonrisa generosa. Entraba al aula con nosotros, iba hasta el lugar del profesor y dejaba la cartera sobre la mesa; se sentaba, la abría, sacaba un puñado de folios reescritos y recorregidos, leía la primera línea y 


\section{perifèria}

Número 16, junio 2012

revistes.uab.cat/periferia - www.periferia.name

empezaba a hablarnos de los númenes o del concepto de modo de producción sin volver prácticamente a mirarlos hasta que acababa la clase. Nos traía el saber como el que trae el pan caliente. Había estado trabajando hasta tarde, a veces toda la noche. No había rutina en sus asignaturas: todo lo que explicaba lo había repensado para nosotros y siempre te sabía a poco, siempre deseabas que llegara la próxima entrega. Un día, en los pasillos, me comentó con una sutil sonrisa gamberra, de provocador: "Hoy les he dicho a los de Antropología Económica que la idea de hombre es una idea moral" -y añadió: "No sé cómo lo voy a justificar en la próximo clase..." Estoy seguro de que, hasta que llegó ese día, sus alumnos pensaron bastante sobre eso, casi tanto como él -porque, como Ramón intentaba que comprendiéramos, "el ser humano no piensa: pensamos":..

Sin embargo, Ramón no sabía quién era. Sabía lo que le gustaba y lo que no le gustaba. No le gustaba Heidegger, por ejemplo, pero compartía con él su amor por el alemán y un excelente dominio de esta lengua. Le gustaba Marx, aunque confesaba que nunca se hubiera llevado bien con él: le dolían las malas pasadas que había jugado a los ácratas, de quienes se sentía muy próximo. Le gustaba Marx, al que, como muchos sabéis, se negaba a considerar un clásico, un autor al que se pudiera entender "mejor ahora, que ha pasado el tiempo"; al que se pudiera comprender sin ponerlo en práctica. Le gustaba Marx -todos los que estuvimos en sus clases lo habíamos oído- porque escribió las verdades más potentes y más sencillas. Que el ser humano crea sus dioses en el mismo proceso de cultivar sus cebollas, por ejemplo -y a mí me encantaba la inocente ironía con que pronunciaba esta frase.

Le apasionaba a Ramón la música y él, que no salía de casa sino para sus clases porque trabajaba en su despacho hasta en domingo, era capaz de tomar un avión para ir a escuchar un buen concierto a cualquier lugar de Europa.

Le gustaban a Ramón las personas raras, los que no encajan muy bien en ningún sitio. Añoraba a su bien amado alumno Alberto Cardín, muerto en el 92, y lloró con amargura a Jaume Corella, que nos dejó tan joven, apenas terminada su tesina.

Le gustó siempre a Ramón exigirse, comprometerse y apasionarse. 


\section{perifèria}

Número 16, junio 2012

revistes.uab.cat/periferia - www.periferia.name

En su penúltima etapa de docencia, la última que yo viví como alumno, redescubrió a Engels y, ayudado por José Luis Molina, organizó en Internet un grupo de trabajo, "Engels y religión", del que me descolgué muy pronto por razones que no vienen al caso. Al final explicaba que su favorito era Trostki porque le parecía el más anarquista de los marxistas.

Quizá Ramón comprendió que, para una persona honesta, no hay empeño más imposible que decidir quién es, ser uno solamente -y que, finalmente, esa decisión no la tomamos nosotros sino el tiempo que se acumula sobre nuestras espaldas, que nos deshoja, que nos quita una a una las contradicciones, las pasiones, cada una de las dimensiones de nuestra alma, hasta dejarnos lisos. Alguna vez le oí citar al Doctor Cardoso del "Sostiene Pereira" y su teoría del ser humano como República de almas, confederación en la que la hegemonía de una de ellas siempre es temporal. Sin embargo, a diferencia de Pereira, el personaje de Antonio Tabucchi, Ramón tomo partido desde muy joven. Tal vez, finalmente, decidió que no sabía quién era esa persona que cada mañana le miraba desde el espejo, pero hay algo que siempre tuvo claro. Desde su primera lucidez hasta que la enfermedad se la arrebató toda, desde que terminó el bachillerato y tuvo que decidir si continuaba estudios a pesar de las penurias de su familia, Ramón siempre supo en qué bando estaba, siempre sintió la pulsión del conocimiento, la necesidad de su búsqueda, -y, sobre todo, supo que ese conocimiento no podía disociarse de una responsabilidad, de un compromiso, que no se podía aprender ni saber sin amar: "Yo siempre he sabido, desde muy niño, quienes eran los míos". -dijo un día, muy serio, en mitad de una charla distendida con alumnos. Por eso, porque lo sabía muy bien, tomo la decisión más difícil de su vida: volver de Alemania, donde su profesor, Baumann, quería que se doctorase con él y le sucediera en la dirección del Instituto de Etnología de la Universidad de Munich. Por eso, después de renunciar a tal privilegio, eligió un Instituto laboral de un pueblecito de Asturias y se implicó en la vida de los paisanos mucho más de lo que suponían sus obligaciones docentes de profesor y director. Por eso enseñó a tantas promociones de alumnos que la antropología, a diferencia de otros saberes, no puede resolver sus problemas sin plantearse cambiar radicalmente la sociedad. Estoy seguro de que Ramón -hoy que

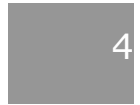




\section{perifèria}

Número 16, junio 2012

revistes.uab.cat/periferia - www.periferia.name

una caterva de banqueros sin escrúpulos, políticos ineficaces y prestigiosos catedráticos de universidades americanas nos están hundiendo- volvería a escribir aquella carta que escribió a sus alumnos de la Autónoma en el 76 y se ofrecería, de nuevo, a ayudarnos a hacer una antropología que clarifique la relación entre nuestra experiencia individual y las cuestiones sociales, entre nuestra biografía y la historia, la Antropología que ya sus alumnos hacen.

Sé que muchos de ustedes han leído la carta; quizá los más jóvenes no. La suscribo toda, pero me quedo con su conclusión a la crítica a la antropología burocratizada: "La cuestión no es si sabemos bastante: la cuestión es si tenemos el valor de saber lo que sabemos, decirlo y usarlo".

Les he contado al principio que conocí a Ramón hace quince años. En realidad no es exacto. Le conocí mucho antes, aunque sin saberlo. Le conocí siendo adolescente, cuando llegó a casa de mis padres un volumen de una enciclopedia divulgativa de las Razas Humanas. No podía yo imaginar que, mucho tiempo después, iba a encontrarme con el autor de aquellas páginas sobre África, que iba a admirarle tanto y a quererle. Un hombre al que, en toda nuestra relación, sólo pude hacerle un reproche que hoy siento mucho más que nunca que se lo merecía. Se lo voy a referir a ustedes: un día, Ramón hizo una observación en clase por la que, aunque no se dirigía a mí, me sentí personalmente interpelado en uno de mis escritos: dijo que el adjetivo "noble" no le gustaba, ni tampoco "vulgar", porque siempre denotaban una mirada elitista. Perdónenme, no soy poeta ni lo seré nunca. Cuando acaben de escucharme verán ustedes que esta aclaración era totalmente innecesaria. No lo había hecho antes y nunca después de aquella ocasión he vuelto a intentarlo, pero me pareció que a Ramón no podía contestarle de cualquier manera, así que junté unos cuantos versos cojos y se los hice llegar camuflados detrás de la última página -página en blanco, página de cortesía- de un trabajo. Había en ello un riesgo: ya saben ustedes que hay profesores que no se leen los trabajos de sus alumnos o simplemente los ojean. Ramón, no. Ramón se los leía a conciencia, así que leyó el trabajo completamente, apuró la copa hasta las heces y encontró, oculto, lo que sigue: 


\section{perifèria}

Número 16, junio 2012

revistes.uab.cat/periferia - www.periferia.name

Ramón, noble mentor: Si un día dijiste

que ese es un adjetivo ingrato,

palabra, con vulgar, que aborreciste

por ser de la injusticia correlato,

perdóname que niegue tu criterio

y escriba este poema desatento;

evoca tu perenne magisterio,

blasón de aristocracia del talento.

No nieguen, pues, tus labios la nobleza

que en tus ojos alienta enamorada:

no es noble ningún hombre por riqueza

ni por sangre. Sólo si su mirada

afirma el mundo con augusta grandeza,

ciega al rencor, sin compasión de nada,

triunfante de la culpa en el suplicio,

merece lauro eterno de patricio.

Ramón era la antítesis de la erudición banal. Encarnaba para mí el saber ético, la nobleza del conocimiento en los dos sentidos del término: en el sentido de excelencia y en el de magnanimidad. Había conocido la crueldad, la tragedia, desde muy niño, pero no se doblegó. Sin replegarse sobre sí mismo y sin albergar sentimientos negativos, sin culpa, rencor ni compasión, luchó a su manera toda la vida, estudiando y dedicándose absolutamente a la docencia de lo que amaba, en el aula y en el resto de su vida pública. Yo creo que cuando Ramón me decía que no sabía quién era él y me demostraba que eso no le importaba, me estaba previniendo contra el ensimismamiento que produce la intuición del dolor, el miedo 


\section{perifèria}

Número 16, junio 2012

revistes.uab.cat/periferia - www.periferia.name

que sólo conduce a la pasividad. Me estaba diciendo que el ser humano es sólo la sombra de su obra, el registro de lo que ha dado y lega a los demás, que lo que tiene valor social es su obra y que, además, ésta ni siquiera es enteramente suya ya que se ha construido con materiales sociales. Yo creo que Ramón no quería que me ocurriese lo que les pasa a las personas que sólo se ocupan de sí mismas, de "lo suyo", personas como tantas que él había encontrado en la Europa de posguerra, como el Hausmeister, el portero del Colegio Español en Munich, que le recibió al llegar allí en enero del 57: "Joven, -le dijo un día- no se crea Vd. nunca que los alemanes no sabíamos lo que pasaba en Dachau. Cuando soplaba föhn, o sea, casi siempre, aquí olíamos la carne quemada. Pero, ¿qué podíamos hacer?".

Lo que hizo Ramón toda su vida: asumir lo que sabía, decirlo y usarlo. iNobleza obliga! 